\title{
Review
}

\section{Inclinations: a critique of rectitude}

\author{
Adriana Cavarero \\ Stanford University Press, Stanford, 2016, viii + 194 pp., \\ ISBN: 9780804792189
}

Contemporary Political Theory (2018) 17, S185-S188. https://doi.org/10.1057/s41296017-0154-7; published online 21 September 2017

In her latest book Adriana Cavarero, Italy's most eminent feminist philosopher, takes a journey through art, literature, history, and philosophy to offer a critique of a geometric figure underlying Western thought: the figure of verticality. This geometry symbolizes a model of subjectivity that represents the ethical and political agent as an erect, autonomous, and rational self. Cavarero argues that this individualistic ontology obstructs the development of an altruistic ethics, for it reduces ethics to abstract principles founded on philosophy's abstract construction of the self. The intention of Inclinations is therefore to challenge, rather than negate, the vertical model of the subject: to "critique its limits, pretences and its uncritical adoption in the fields of ontology, ethics and politics" (p. 128). The figure of the inclining mother provides the imagery from where Cavarero extracts an alternative narrative that she superimposes over the rhetoric of the philosophical subject. She thus contrasts the two models of subjectivity underlying ontology, ethics, and politics: an individualistic and a relational model. By rethinking subjectivity through the category of relation, we can expand the geometry of our thinking in order to clear the ground for an altruistic ethics of relationality based on vulnerability and dependence. Inclinations thus complements Cavarero's political project developed in For more than one voice (2005).

Despite the significant role of beginning in her work, it seems that her point of departure is in fact to be found at the end of the book, where she closes with a notably long Coda on Levinas' ethical legacy. She comments that, in contrast to many contemporary post-structuralist scholars, Levinas does not aim to deconstruct the subject, but rather to reconstruct it. By translating human plurality and uniqueness (Arendtian categories so dear to Cavarero) into ethical terms, he endeavors to develop an ethics of relationality. Cavarero concludes, however, that Levinas's conceptualization of the subject derived from the figure of uprightness and the metaphysical category of death lead him to postulate a radical pacifism as the foundation for politics. This verticality in Levinas's work constitutes the

(c) 2017 Macmillan Publishers Ltd. 1470-8914 Contemporary Political Theory Vol. 17, S4, S185-S188 
rationale of Inclinations: Cavarero aims to tackle this obstacle for rethinking ethics and politics in terms of relationality and vulnerability.

In the first half of the book, Cavarero systematically exposes the dualism underlying Western thought: the geometry of verticality designating the moral rectitude of an autonomous rational subject on the one hand, and the inclining posture, i.e., the leaning towards sin and wrong, on the other. Drawing, inter alia, on the philosophical work of Kant and Locke, as well as on art works by Barnett Newman, Cavarero argues that the erect posture is conceptualized as masculine. This is exemplified by Adam, created by god as a fully developed adult, who avoids the stage of childhood, and, with it, the stage of vulnerability and dependence. In contrast, the figure of inclination is associated with the natural being of humans: its desires and affection are ascribed to the weaker sex, the female. In Kant's work, however, the Cartesian subject repudiates any kind of inclination towards other people, and further ignores the vulnerability and the asymmetry of human affairs.

However, the figure of inclination has not always been used negatively, as Cavarero points out. In Hobbes's political thought, for instance, equality is founded in the natural inclination towards homicide. Yet, inclination in this example still carries the notion of $\sin$ and thus conforms to the dominant narrative favoring verticality. In order to flesh out the inclined figure and extract it from its metaphorical concealment, Cavarero therefore links inclination to creative power. In this context, she discusses Artemisia Gentileschi's Allegoria dell'inclinazione (Allegory of Inclination), where inclination represents a natural predisposition for art.

Cavarero follows Hannah Arendt's rejection of the metaphysical tradition and its focus on death, and then shifts the focus to the category of natality, which she expands on in chapter eleven. Birth is not seen simply as a natural phenomenon, but as a scenario that is constitutive of the human experience of beginning. Cavarero distinguishes between two understandings of birth in Arendt: the first, which refers to childbirth, and the second, which refers to political action with others as a form of birth, in which a person enters the "relational space of reciprocal appearance" (p. 109). She dismisses Arendt's focus on the latter because, even though it derives the idea of uniqueness and contingency from the phenomenon of childbirth, it possesses a different connotation. Arendt's political space is structurally relational, but, in contrast to the asymmetrical dependency of childbirth, it is essentially characterized by reciprocity and interdependence. Arendt's reference to Genesis, as Cavarero points out, is thus not trivial, as she ignores the fact of infancy in the scene of birth; for Arendt, the newborn is not an infant but Adam, who enters the world as an equal. As a consequence, she argues, Arendt's abstraction of the birth scene is misleading. Rather, it is the notion of maternity that holds "vulnerability and relationally together in an inseparable ontological bond" (p. 122). According to Cavarero, it is only in this sense that the category of birth has the potential to generate the grounds for an altruistic ethics of relationality and a politics that can be 
based on a positive anthropological presupposition, along the lines Levinas proposes. Embellishing the cover of this book, the picture of the Madonna inclining over the new born, so prominent in Renaissance Italy, serves Cavarero as a symbol for this ethics which needs yet to be thought (p. 174).

On a closer reading, several issues emerge. In spite of Cavarero's indicating that she is deliberately exaggerating in order to draw out the dominant individualistic ontology underpinning the figure of verticality (p. 10), her geometric reading seems slightly forced at times. Levinas never explicitly uses figures of verticality in his work, which is why Cavarero needs several steps to excavate his notion of uprightness from the texts. Similarly, post-structuralist scholars might be unsatisfied with her aim to "submit the egocentric verticality to a detailed deconstruction" (p. 11). They might also disagree with her exaggeration of the dualism of male and female ontology as "part of the method" (p. 101) she uses to contrast an individualistic and a relational model of ethics. Her intention is not to replace the male idea of the subject with a female model, but instead to discard its paradigmatic force and to rethink ontology in various geometrical postures. The promotion of a maternal ethical posture, however, seems to manifest - rather than undermine - a patriarchal order over the course of the book.

Furthermore, not every reader will be convinced by Cavarero's renouncing the abstraction implicit in Arendt's concept of natality. In the Coda she points out how the comparison Levinas draws between the fear a mother feels for her child's death and the fear we might experience for a friend's death is implausible and lacks "exemplary efficacy" (p. 166). Despite this, Cavarero never addresses the possible issues arising from grounding an ethics in the relationship between mother and child and from the generalization of a kinship relationship. In contrast, Arendt's abstract understanding of birth makes it applicable to various political situations: the newcomer might be the immigrant who enters an existing political community, or the formerly oppressed person whose voice is now being heard. By placing the mother-child relationship to the heart of the category, Cavarero addresses the issues of dependence and vulnerability. At the same time, however, she risks overstretching this category when it is supposed to cover relations that are not kinship-based but are purely political. It would have been useful if she had more clearly elaborated on the political implications this revised ethics has for general human affairs. Notwithstanding the illuminating critique of the history of philosophical ontology, the reader is left wanting for Cavarero to elaborate on the merits of her proposal.

Inclinations showcases Cavarero's unique way of using geometrical figures to connect philosophical texts as well as various examples from art and literature. They serve to access the cultural resources underpinning our understanding of what it is to be human and to lay bare the bones of our thought. As we move through the chapters, we find her exposing the upright imaginary through masterfully formulated reconstructions of a vertical solid self that cannot bend towards the

(C) 2017 Macmillan Publishers Ltd. 1470-8914 Contemporary Political Theory Vol. 17, S4, S185-S188 S187 
other. The Arendtian mode of thinking ontologically from human experience, as well as the political role Arendt ascribed to storytelling are omnipresent, although Cavarero's writing seems more playful and light-hearted than her teacher's. As in previous work, she follows Luce Irigaray's emphasis on sexual difference in order to create and express a female narrative. Cavarero is thus able to find a unique and refreshing voice.

\section{Reference}

Cavarero, Adriana. (2005) For More than One Voice. Stanford: Stanford University Press.

Viktoria Huegel

University of Brighton, Brighton BN2 4AT, UK v.huegel@brighton.ac.uk 